\title{
Analysis on Micro-lecture Design in Modern Distance Education Ying Yang ${ }^{1, a}$,Xiaohui Zhang ${ }^{2, b}$,Dan Tian ${ }^{3, c}$ \\ ${ }^{1,}$ School of Distance and Continuing Education,DaLian University of Technology,DaLian 116011, China \\ 2, school of computer and information technology,Liaoning Normal University,DaLian 116001, China \\ ${ }^{3,}$ School of Distance and Continuing Education,DaLian University of Technology,DaLian 116011 ,China \\ ae-mail:net15@dlut.edu.cn
}

Keywords:Micro-lecture, Distance education,Instructional design,Instructional strategies

\begin{abstract}
Recently, Micro-teaching has become a milestone in the development of modern distance education. It adapts the needs of distance education by the learning characteristics of fragmentation. Due to the particularity of teaching and learning, Micro-lecture Design in Modern Distance Education is different from that in traditional face-to-face teaching. Students should be centered in the instructional design of distance education courses, and be assisted by teachers to complete their study. Then interaction with the students for heuristic learning should be focused on. Teachers should determine the content and target of Micro-lecture by a student's standing point, and take appropriate instructional strategies.
\end{abstract}

\section{Introduction of Micro-Lecture}

With the rapid development of Internet technology, various elements of education and teaching system are also changing. And Micro-lecture was born as a new kind of educational model. In the sense, Micro-lecture is a kind of small course with shorter teaching time and relatively less contents. The main feature of Micro-lecture is that learners can learn by their fragment time, and accumulate the knowledge one by one.

Micro-lecture has distinctive features.

Firstly, Education is the most important feature of Micro-lecture. It can transmit teaching information to the learner and help them to learn rapidly.

Secondly, Micro-lecture has its purpose. It can help the learner understand and grasp the learning content briefly by its clear teaching objectives and prominent knowledge points.

Thirdly, Micro-lecture is much more interesting compared with traditional curriculum. It has many forms with the aid of the network technology, such as videos, cartoons, PowerPoint and so on. So the learner can learn more lively.

Fourthly, Micro-lecture has extensive sharing as a kind of learning resource and learning mode. It adapts with mobile learning, online learning and ubiquitous learning.

For distance education, the teachers and students are separate, and the students mainly learn by themselves. Then the Micro-lecture just adapts the needs of distance education by its features.

\section{Problems of Micro-Lecture Design}

Micro-lecture imposed a micro video as the core, supplemented by teaching design, teaching courseware, teaching reflection, etc to help learners to the completion of independent learning. Whether micro-video can achieve autonomy, individualized learning, teaching design plays a vital role. Teaching design plays the soul role both in traditional teaching and information technology teaching, and it will inevitably become the focus of content for Micro-lecture is a kind of teaching activities. So, Micro-lecture design becomes the essential path before Micro-lecture teaching. In the environment of information, Micro-lecture refers to learning content analysis, learner characteristics analysis, teaching goal analysis, teaching strategy design, media selection and application, learning 
situation creation, learning resource design, autonomous learning or collaborative learning strategy design, classroom teaching structure process design, evaluation design and reflection and so on.

Currently, there are some problems of teachers in Micro-lecture design.

At first, some teachers has not correct concept of Micro-lecture design. Micro-lecture construction is used for the teachers' grading, or Micro-lecture is transcribed by traditional classroom directly. Micro-lecture construction practicality is poor without according to the students' actual needs. Then learners can not use the Micro-lecture efficiently.

Then, there are only few forms of the existing Micro-lecture. Existing Micro-lecture mainly refers to video recording, curriculum teachers recording and screen recording. Students will be boring of the simple video recording with no cartoon, audio and atlas.

At last, the current Micro-lecture is remaining based on the teachers, similar as the traditional teaching. It can not effectively lead the students to learn by themselves without the reflection between teachers and students.

So, effective system of Micro-lecture design must be established, in order to play the greatest effect of Micro-lecture. Then the Micro-lecture can make full use of modern information technology means and take advantage of the traditional teaching.

\section{Development Direction of Micro-Lecture in Modern Distance Education}

\subsection{Selection of Teaching Content}

Micro-lecture is short and pithy, but the production is not easy. Not all the courses, teaching contents, and knowledge are suitable for Micro-lecture. Rational design of teaching contents can close the distance between teachers and students, and attract more students to study. The teaching contents suitable for Micro-lecture need to be relatively independent, typical and common. And the forms can be various, such as teaching, problem-solving, Q \& A, training, and so on. Taking 'Bridge Construction' Course as an example, a construction process can be selected to teach learners by some details in the form of Micro-lecture. If the bored pile construction process is selected, several Micro-lectures can be made. Such as the role of protecting tube, the production and types of protecting tube, protecting tube embedment and sink, the role of mud, the preparation of mud, the cycle of mud and purification treatment, and so on. Each construction process Micro-lecture will be finished in 10 minutes. So students can utilize the concentration time for efficient learning. Furthermore, students can complete their learning in fragment time.

Contents of Micro-lecture can be designed for different people. For learners who learn by network, extracurricular expanding knowledge or work related practical knowledge are needed in their spare time. According to this character, teachers can make the teaching video on knowledge teaching or operation show by considering learner's needs. Then the students can acquire the knowledge they want after Micro-lecture video. Meanwhile, Micro-lecture design should be a complete curriculum with continuous system, so students can learn systematically.

\subsection{Characteristics of Learners}

Teachers should have a good understanding of the basic situation of students before teaching activities. Teaching methods should be different for different learners in the same lecture and content. For distance education students, learning needs to be arranged in their spare time. And there are many cross-professional and zero-based students. Micro-lecture should be short, concise, simple, acceptable and common, and be introduced continuously. Prompt information should be given in the related text information, such as bright colors, underline, tips, etc. Conclusion part can be carried out after each Micro-lecture to help students to clarify their thinking and grasp the important and difficult content. 


\subsection{Design of Teaching Strategies and Teaching Resources}

Design of teaching strategies and teaching resources plays an important role in Micro-lecture design. Whether the students would be attracted or not depends on the teacher's teaching mode and teaching resources. Teachers should deliver their teaching contents by rich and colorful teaching forms, and then students can get the knowledge in a happy learning. Taking 'Bridge Construction' Course as an example also, teachers can adopt variety forms of resources to assist teaching in the process of course teaching. Knowledge can be taught aided by the construction site photos (Figure.1).

Cartoons and videos can make the course more interesting for students. So videos of the key construction parts and construction methods are more intuitive for students. Teachers can make a bridge model to explain in site or introduce the experimental facilities in laboratory (Figure.2).

Video and PowerPoint can also be combined in teaching process, for there is few communication between teachers and student in the form of video only. And students are easy to be boring of PowerPoint teaching only. There are also some other teaching forms can be used in Micro-lecture, such as autonomous learning, group discussions, revealing questions, etc.
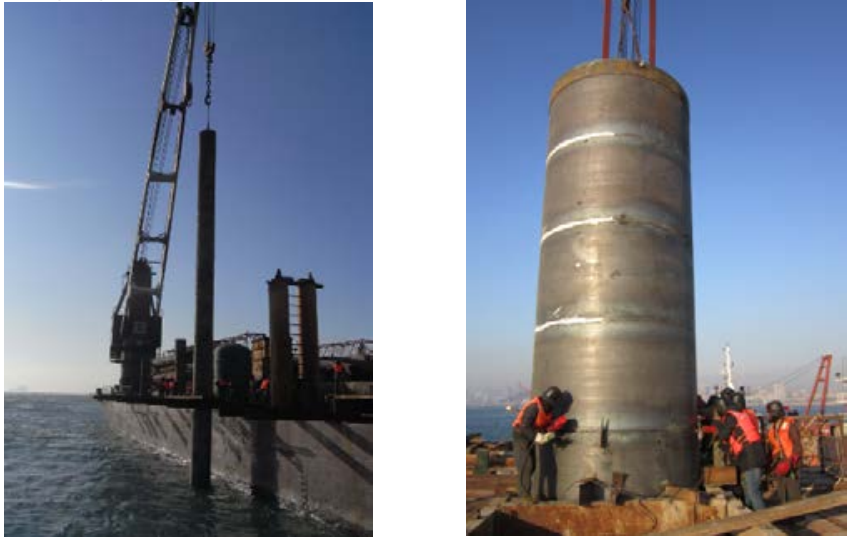

Figure.1 Construction Site Photos of a Bridge
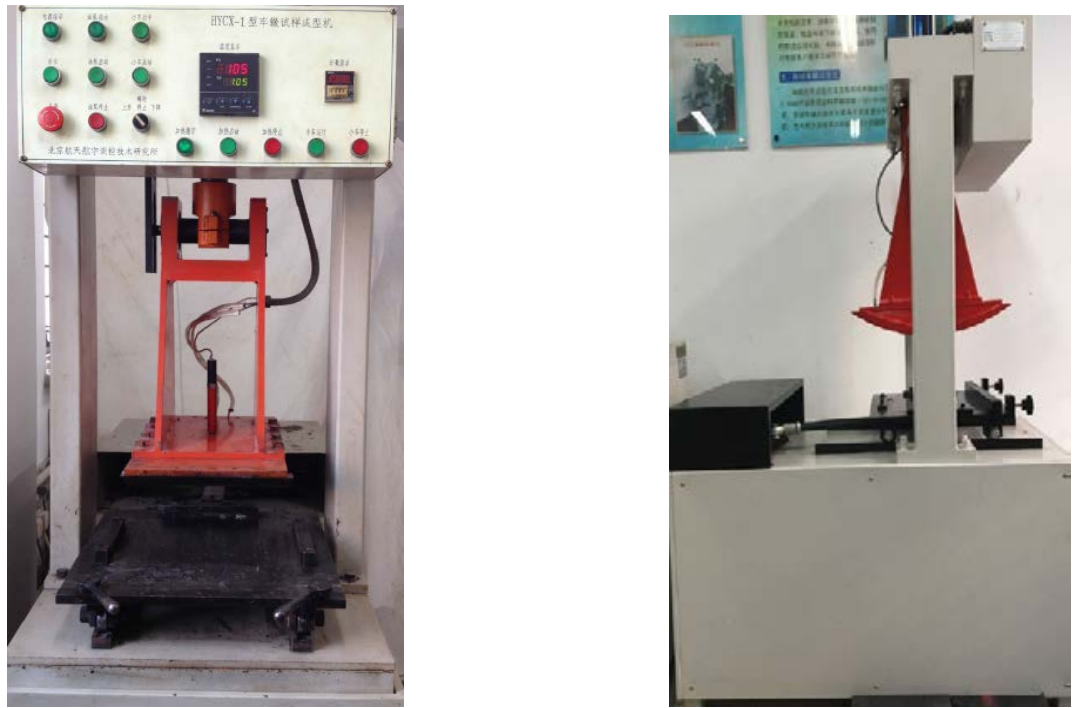

Figure.2 Asphalt Mixer Wheel Crusher

\subsection{Design of Teaching Evaluation}

As an education form, the teaching evaluation system is necessary for Micro-lecture, besides courses teaching. Evaluation form and assessment form in a Micro-lecture should be introduced before teaching, and then students can learn objectively. As a measuring stick of teaching 
achievements, the teaching evaluation is essential both in traditional teaching and information Micro-lecture.

There are many evaluation forms for Micro-lecture with the using of information technology. Evaluation subject can be various. Teachers' evaluation of the traditional teaching can be transferred to evaluation from teachers and students, or homework evaluation between students. This not only reduces the teachers' stress of homework, but also promotes the students' autonomous learning. And then competition circumstance is produced and used to increase students' learning motivation.

\section{Conclusion}

Micro-lecture provides the distance education learns a more flexible way of learning and a wider learning platform by its characteristics of tiny and brief. Learners can get the knowledge at any time and in any space by mobile terminals.

By now, there are still some shortages of Micro-lecture design. More teachers and studies are needed for using Micro-lecture to teaching better. Micro-lecture needs to be improved with the changing of learners' demands, and distance education teachers should innovate constantly by a variety of information technology. Micro-lecture design will become an important way of improving the teaching effect and teaching quality of modern distance education.

\section{References}

[1] MichaelMoore, GregKearsley. Distance Education System View[M]. Shanghai Higher Education Electronic Audio and Video Press, 2008

[2] Myung-Suk Lee, Yoo-Ek Son. A Study on the Adoption of SNS for Smart Learning in the Creative Activity[J].International Journal of Education and Learning, 2012,(1):1-18.

[3] Shieh, D. These Lectures Are Gone in 60 Seconds [J]. Chronicle of Higher Education, 2009,(26):1-13.

[4] Kee.T.P.The ore minute Lecture[J]Education in Chemistry 32: $100-101$.

[5] McGrew, L. A. A 60-Second Course in Organic Chemistry[J].Journal of Chemistry Education, 1993,(7): 543-544. 